\title{
Long non-coding RNAs in gastric cancer: mechanisms and potential applications
}

\author{
Ismael Riquelme ${ }^{1,2}$, Carmen Ili, ${ }^{1,2}$, Juan Carlos Roa ${ }^{3}$ and Priscilla Brebi, ${ }^{1,2}$ \\ ${ }^{1}$ Molecular Pathology Laboratory, Department of Pathology, Universidad de La Frontera, Temuco, Chile \\ ${ }^{2}$ Scientific and Technological Bioresource Nucleus (BIOREN), Universidad de La Frontera, Casilla, Temuco, Chile \\ ${ }^{3}$ Department of Pathology, UC Centre for Investigational Oncology (CITO), Advanced Centre for Chronic Diseases (ACCDiS), \\ Pontificia Universidad Católica de Chile, Santiago, Chile \\ Correspondence to: Priscilla Brebi, email: brebimieville@gmail.com \\ Keywords: long non-coding RNAs, gastric cancer, biomarkers \\ Received: January 11,2016 Accepted: April 26, $2016 \quad$ Published: May 17, 2016
}

\section{ABSTRACT}

Gastric cancer is the third leading cause of cancer mortality worldwide. Unfortunately, most gastric cancer cases are diagnosed in an advanced, non-curable stage with a limited response to chemotherapy. Recent findings in gastric cancercausing gene expression mechanisms, however, hold promise for the development of more effective diagnostic and treatment strategies. A novel mechanism for gene expression control mediated by long non-coding RNAs (IncRNAs) has been described, which have emerged as pivotal regulatory components orchestrating extensive cell processes and connections within eukaryotic cells. LncRNA-based mechanisms alter cell fates during development, and their deregulation underscores many human disorders, including gastric cancer. Recent studies have reported that several IncRNAs are aberrantly expressed and linked to the onset and progression of this malignancy. These IncRNAs have gained value for such clinical purposes as novel biomarkers and therapeutic targets; yet despite this potential, many issues remain in this rapidly growing field. This review summarizes the classification and role of IncRNAs, and provides an updated overview of the feasibility of IncRNAs as diagnostic and prognostic tools in clinical samples and as potential therapeutic targets in GC patients.

\section{INTRODUCTION}

Gastric cancer (GC) is the fifth most frequently diagnosed cancer and the third most lethal malignancy worldwide, making it an important public health problem. Every year almost one million new GC cases are diagnosed and $\sim 700,000$ people die of this disease, which is $\sim 10 \%$ of the world's cancer-related deaths [1]. Its high mortality rate is associated with a lack of validated screening programs and the absence of significant symptoms at early stages [2,3]. Consequently, most GC cases are diagnosed at an advanced stage, with a poor prognosis due to the limited efficacy of conventional chemotherapy and surgery $[4,5]$. The high mortality rate and poor prognosis of this disease means that primary prevention, early diagnosis and accurate follow-up should be high priorities $[6,7]$.

$\mathrm{GC}$ is a heterogeneous disease, both histologically and genetically, and patient outcome is difficult to predict using classic histological and molecular classification criteria $[8,9]$. Although the current histological classification of GC is well accepted and several tumor markers such as carcinoembrionyc antigen (CEA), CA19.9 and CA50 are routinely used by clinicians, their low sensitivity and specificity $[8,10,11]$ renders the prognosis and predictive value of this system insufficiently accurate to guide patient management. More recently, epigenetic markers such as microRNAs and DNA methylation status have been proposed as novel biomarkers for $\mathrm{GC}$ due to the promising results including a high pathological correlation, tumor specificity and the fact almost any kind of biological specimen is amenable to study these phenomena. However, these markers show some challenges such as few of these epigenetic markers have been adequately validated for routine clinical use; the assays for these epigenetic biomarkers are diverse; gene lists are large; comparative data are 
few, and disagreements in published papers are frequent [12]. Therefore, the development of accurate biomarkers that robustly and efficiently diagnose GC is imperative, particularly in early stages of this malignancy.

Recent advances in high-throughput technologies have led to the discovery of new transcripts in several types of carcinomas. Long non-coding RNAs (lncRNAs) have emerged as promising epigenetic biomarkers in the diagnosis and prognosis of human disease; these molecules are particularly attractive due to their close association with different cancers and their cell-specific expression [13, 14]. Recently, Li et al. [15] have described the mechanisms of lncRNAs interactions with DNA, RNA and proteins on GC, in a more molecular manner. On the other hand, in this review we summarize the last knowledge about the biogenesis and classification of lncRNAs and the feasibility of IncRNAs as diagnostic and prognostic tools in clinical samples and as potential therapeutic targets in order to evaluate their clinical utility for improving GC patient survival.

\section{LONG NON-CODING RNAS (LNCRNAS): CHARACTERISTICS AND CLASSIFICATION}

Non-coding RNAs (ncRNAs) are RNA transcripts that do not encode for a protein and that comprise two main categories: small ncRNAs (sncRNAs) shorter than $200 \mathrm{bp}$ and long ncRNAs (lncRNAs) longer than 200 bp to over $10 \mathrm{~kb}$ [16]. Currently, a lncRNA is defined as a polyadenylated long ncRNA transcribed by RNA polymerase II and linked to the epigenetic regulation of protein-coding genes, binding to DNA, proteins and/or other RNAs $[17,18]$. The malleable adoption of secondary and tertiary structures relating to function is one of the most intriguing features of lncRNAs [19].

New high-throughput technology such as RNA sequencing (RNA-Seq) suggests that several thousand uncharacterized lncRNAs are present in any given cell type (differentiated cells or stem cells). As many lncRNAs show a tissue-specific expression, it is suspected that the human genome may harbor as many lncRNAs as proteincoding genes (perhaps $\sim 15,000$ lncRNA), although only a fraction are expressed in a given cell type [20-22]. The several differences among lncRNAs in terms of structure, function, location and action mechanisms make lncRNA classification difficult. Authors have classified lncRNAs according to their different features, including their (1) genome location and context, (2) exerted effect on DNA sequences, (3) mechanism of functioning, and (4) targeting mechanism [23].

\section{Genome location and context}

According to the genome location and context classification, lncRNAs can be grouped into five broad but mutually non-exclusive categories according to the GENCODE annotation [24] (Figure 1). Those transcribed from intergenic regions are called intergenic IncRNAs and, in contrast, those transcribed entirely from introns of protein-coding genes are called intronic lncRNAs. This suggests that intergenic lncRNAs and intronic $\operatorname{lnc} R N A s$ are most likely controlled by different transcription activation mechanisms and may have different poly(A) modifications. Long intergenic non-coding RNAs (lincRNAs) have been more extensively studied than intronic RNAs in terms of expression, function and conservation among species [23]. A third group of lncRNAs, so-called pseudogenes, are defined as the "relics" of genes that have lost their coding potential due to nonsense, frameshift, and other mutations [25]. Many pseudogenes are products of tandem gene duplication or products of mRNAs being carried along during retrotransposition, both of which create extra gene copies that are no longer under selective pressure. The vast majority of pseudogenes are no longer expressed and their genetic sequences drift at a neutral rate. However, some are transcribed (from 2 to $20 \%$ ) and alter the normal gene expression (often of their ancestral coding genes) by epigenetic or post-transcriptional mechanisms [26].

LncRNAs can be sub-classified in sense and antisense types. Sense lncRNAs are transcribed from the sense strand of protein-coding genes, overlapping with part of the protein-coding exon, or cover the entire sequence of a protein-coding gene. Conversely, antisense IncRNAs are transcribed from the antisense strand of protein-coding genes $[27,28]$. Interestingly, both types can also be multi-exonic. About $32 \%$ of the human lncRNAs are antisense to coding genes, suggesting that this regulation is likely commonly used. However, compared to lincRNAs and antisense lncRNAs, sense lncRNAs have been less explored in functional terms [26].

All these lncRNAs show different mechanisms of action: cis or trans transcriptional regulation, translational control, splicing regulation, post-transcriptional regulation, and others that will be explained then [23].

\section{Effects exerted on DNA sequences}

LncRNAs are predominately localized in the nucleus surrounding the chromatin, suggesting that lncRNAs may significantly influence DNA sequences. Also, a large proportion of lncRNAs are involved in transcriptional regulation $(\sim 42 \%)$ [23]. Therefore, cis-lncRNAs (cisacting lncRNAs) are defined as exerting effects on DNA sequences of genes in close genomic proximity. These lncRNAs more easily influence genes in the immediate vicinity of the locus from which they are transcribed, 


\section{A Intergenic}

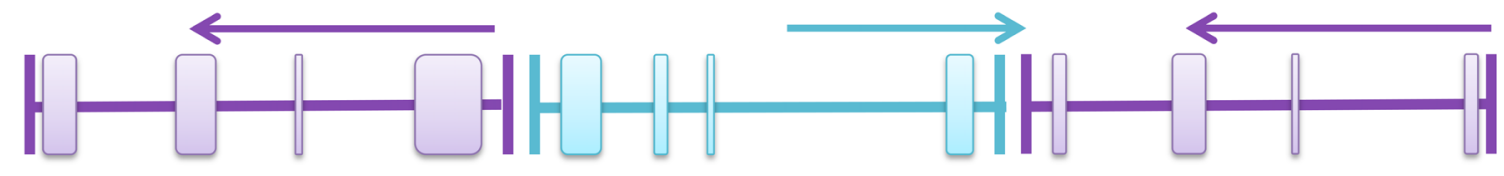

\section{B Intronic}

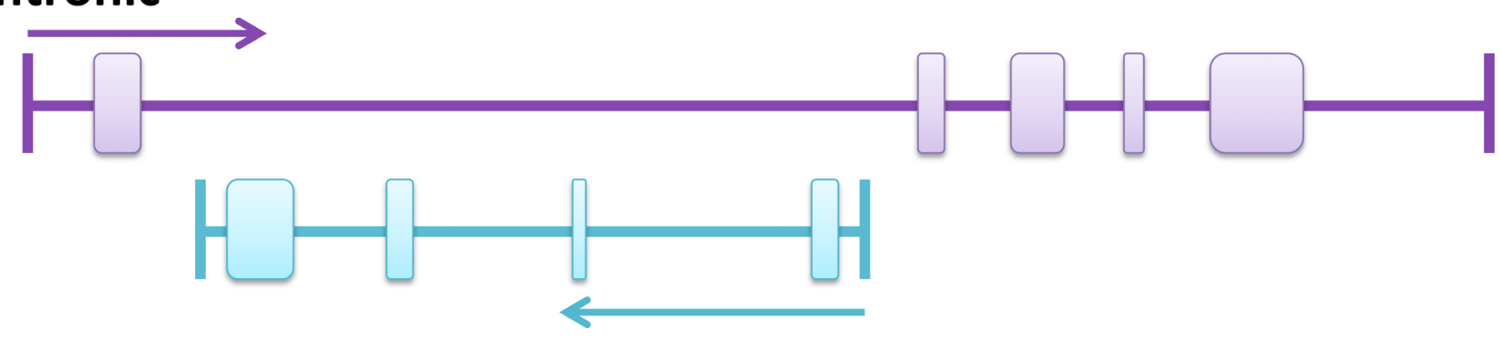

\section{Pseudogene}

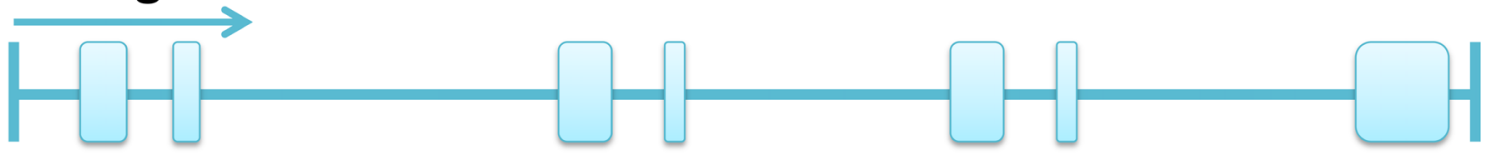

\section{Sense}

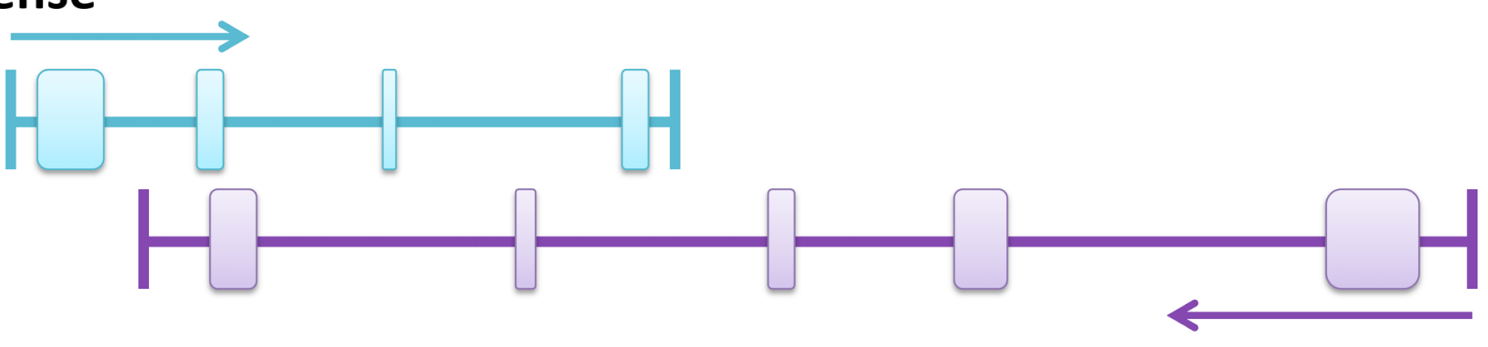

\section{E Antisense}

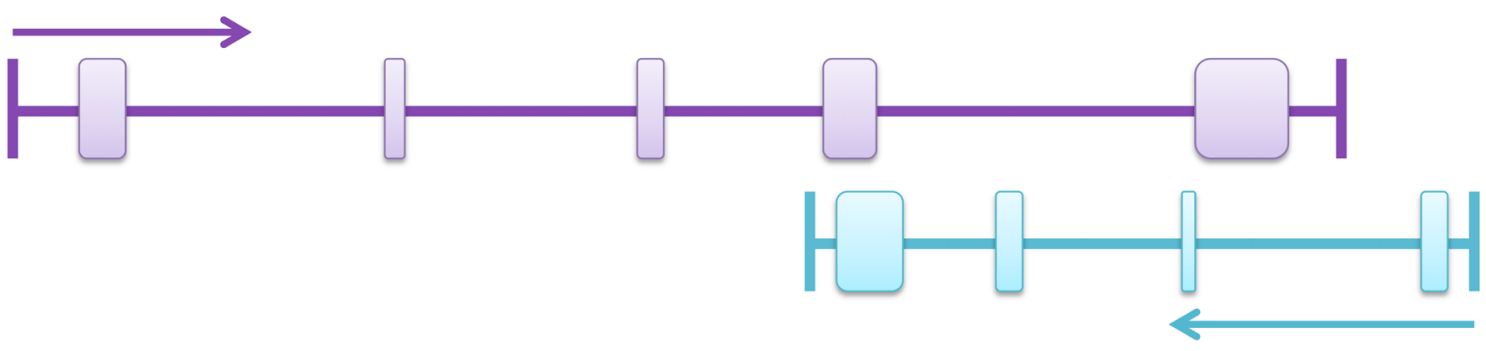

\section{Coding $\square$ Non-Coding}

Figure 1: Genomic location and context of IncRNAs. Protein-coding genes and their exons are in purple, while lncRNAs and their exons are in light blue. Panels are mainly based on lncRNA location annotation from GENCODE. A. Intergenic lncRNA, transcribed intergenically from both strands. B. Intronic lncRNA, transcribed entirely from introns of protein-coding genes. C. Pseudogene, transcribed from the "relics" of genes that have lost their coding potential due to nonsense, frameshift, or other mutations, or the product of tandem gene duplication or of mRNAs carried along during retrotransposition, both of which create extra gene copies no longer under selective pressure. D. Sense lncRNA, transcribed from the sense strand of protein-coding genes and contains exons from protein-coding genes, overlapping with part of protein-coding genes or covering the entire sequence of a protein-coding gene through an intron. E. Antisense IncRNA, transcribed from the antisense strand of protein-coding genes, overlapping with exonic or intronic regions or covering the entire protein-coding sequence through an intron. 
Table 1: Long non-coding RNAs with known or putative involvement in gastric cancer.

\begin{tabular}{|c|c|c|c|c|c|c|}
\hline LncRNA & Alias & GenBank & Gene ID & Expression & Functions & References \\
\hline ABHD11-AS1 & $\begin{array}{l}\text { WBSCR26; } \\
\text { LINC00035; } \\
\text { NCRNA00035 }\end{array}$ & BU595969.1 & 171022 & $\begin{array}{l}\text { Down } \\
\text { Up }\end{array}$ & Unknown & {$[29,80]$} \\
\hline AI364715 & - & AI364715 & - & Down & Unknown & {$[71]$} \\
\hline LINC00668 & - & LINC00668 & 400643 & Up & $\begin{array}{l}\text { Cell cycle regulation } \\
\text { Cell proliferation }\end{array}$ & [97] \\
\hline AK054978 & LINC00632 & AK054978.1 & 286411 & Up & Unknown & {$[56]$} \\
\hline AK058003 & $\begin{array}{ll}\text { SNCG; } & \text { SR; } \\
\text { BCSG1 } & \end{array}$ & AF044311.1 & 6623 & Up & Hypoxia & {$[82]$} \\
\hline AK091883 & - & AK091883 & - & Down & Unknown & {$[87]$} \\
\hline AKR7A2P1 & AFARP1 & AJ277796.1 & 246182 & Down & Unknown & {$[29]$} \\
\hline ANRIL & $\begin{array}{l}\text { CDKN2B-AS1; } \\
\text { p15AS; PCAT12; } \\
\text { CDKN2BAS; } \\
\text { CDKN2B-AS; } \\
\text { NCRNA00089 } \\
\end{array}$ & BC038540.1 & 100048912 & $\mathrm{Up}$ & Cell growth Regulation & {$[98]$} \\
\hline ASHG19A3A007184 & - & - & - & Down & Unknown & [99] \\
\hline ASHG19A3A028863 & - & - & - & Up & Unknown & [99] \\
\hline BQ213083 & $\begin{array}{l}\text { LINC01317; } \\
\text { AC009499.1 }\end{array}$ & BQ213083.1 & 104355287 & Up & Unknown & {$[29,56]$} \\
\hline DB077273 & $\begin{array}{l}\text { GACAT1; } \\
\text { LINC00876; } \\
\text { AC096655.1-002 } \\
\end{array}$ & DB096621.1 & 104326057 & $\begin{array}{l}\text { Up } \\
\text { Down }\end{array}$ & Unknown & {$[29,56,73]$} \\
\hline FER1L4 & C20orf124 & AL121586.31 & 80307 & Down & Unknown & {$[29,56]$} \\
\hline GACAT3 & AC130710 & BX375330.2 & 104797537 & $\mathrm{Up}$ & Unknown & {$[29,76]$} \\
\hline GAS5 & $\begin{array}{l}\text { SNHG2; } \\
\text { NCRNA00030 }\end{array}$ & AF088026.1 & 60674 & Down & Cell proliferation & {$[85]$} \\
\hline H19 & $\begin{array}{l}\text { ASM; BWS; } \\
\text { WT2; ASM1; } \\
\text { D11S813E; } \\
\text { LINC00008; } \\
\text { NCRNA00008 }\end{array}$ & AF087017.1 & 283120 & Up & $\begin{array}{l}\text { Tumor growth } \\
\text { Proliferation }\end{array}$ & $\begin{array}{l}{[29,53,55-} \\
57,62,99]\end{array}$ \\
\hline HMlincRNA717 & $\begin{array}{l}\text { GACAT2; } \\
\text { MTCL1AS1; } \\
\text { MTCL1-AS1 }\end{array}$ & BM709340.1 & 100287082 & Down/Up & $\begin{array}{l}\text { Metastasis } \\
\text { Venous invasion } \\
\text { Nervous invasion } \\
\end{array}$ & {$[56,72]$} \\
\hline HOTAIR & $\begin{array}{l}\text { HOXAS; } \\
\text { HOXC-AS4; } \\
\text { HOXC11-AS1; } \\
\text { NCRNA00072 }\end{array}$ & DQ926657.1 & 100124700 & $\mathrm{Up}$ & $\begin{array}{l}\text { Chromatin } \\
\text { organization } \\
\text { Invasion }\end{array}$ & $\begin{array}{l}{[30,40,42-} \\
44,47]\end{array}$ \\
\hline HULC & $\begin{array}{l}\text { HCCAT1; } \\
\text { LINC00078; } \\
\text { NCRNA00078 }\end{array}$ & - & 728655 & Up & $\begin{array}{l}\text { Cell proliferation } \\
\text { Apoptosis } \\
\text { Tumor metastasis }\end{array}$ & {$[78,100]$} \\
\hline LINC00152 & $\begin{array}{l}\text { C2orf59; } \\
\text { NCRNA00152 }\end{array}$ & BC009508.2 & 112597 & Up & \begin{tabular}{|l|} 
Cycle arrest \\
Apoptosis \\
EMT \\
Migration and invasion \\
\end{tabular} & $\begin{array}{l}{[29,63,65-} \\
67]\end{array}$ \\
\hline LINC00261 & $\begin{array}{l}\text { ALIEN; } \\
\text { DEANR1; } \\
\text { HCCDR1; } \\
\text { C20orf56; } \\
\text { NCRNA00261; } \\
\text { onco-IncRNA-17 }\end{array}$ & - & 140828 & Down & $\begin{array}{l}\text { Cardiovascular } \\
\text { development }\end{array}$ & {$[65,101]$} \\
\hline
\end{tabular}




\begin{tabular}{|c|c|c|c|c|c|c|}
\hline $\begin{array}{l}\text { IncRNA: } \\
\text { chr2:118381039- } \\
118383698\end{array}$ & LEIGC & - & - & Down & $\begin{array}{l}\text { Tumor growth } \\
\text { Proliferation } \\
\text { Migration } \\
\text { EMT inhibition }\end{array}$ & [86] \\
\hline ncRuPAR & NCRNA00193 & - & 100302746 & Down & Angiogenesis & [70] \\
\hline PVT1 & $\begin{array}{l}\text { LINC00079; } \\
\text { NCRNA00079; } \\
\text { onco- } \\
\text { lncRNA-100 }\end{array}$ & M31519.1 & 5820 & Up & $\begin{array}{l}\text { Cell proliferation } \\
\text { Apoptosis inhibition }\end{array}$ & {$[65,102,103]$} \\
\hline RMRP & $\begin{array}{l}\text { CHH; } \quad \text { NME1; } \\
\text { RRP2; RMRPR }\end{array}$ & M29916.1 & 6023 & Up & \begin{tabular}{ll|} 
Development and \\
growth \\
Tumorigenesis
\end{tabular} & [29] \\
\hline RPPH1 & $\begin{array}{l}\text { H1RNA; } \\
\text { RPPH1-1 }\end{array}$ & X15624.1 & 85495 & Up & $\begin{array}{lr}\text { Component } & \text { of } \\
\text { the RNase } & \mathrm{P} \\
\text { ribonucleoprotein } & \end{array}$ & [29] \\
\hline SDMGC & - & - & - & $\mathrm{Up}$ & Migration/invasion & {$[87]$} \\
\hline SNHG1 & \begin{tabular}{|l|} 
UHG; U22HG; \\
LINC00057; \\
NCRNA00057 \\
\end{tabular} & L36588.1 & 23642 & Up & Unknown & {$[65]$} \\
\hline SUMO1P3 & - & L36588.1 & 474338 & $\mathrm{Up}$ & Unknown & [75] \\
\hline SPRY4-IT1 & - & AK024556.1 & 100642175 & $\begin{array}{l}\text { Up } \\
\text { Down }\end{array}$ & $\begin{array}{l}\text { Cell growth } \\
\text { Migration and invasion } \\
\text { EMT }\end{array}$ & {$[83,84]$} \\
\hline TUG1 & $\begin{array}{l}\text { TI-227H; } \\
\text { LINC00080; } \\
\text { CRNA00080 }\end{array}$ & AK057695.1 & 55000 & Up & $\begin{array}{l}\text { Cell proliferation } \\
\text { Apoptosis inhibition }\end{array}$ & {$[65]$} \\
\hline XGPY2 & $\begin{array}{|ll|}\text { XG; } & \text { XGPY; } \\
\text { XGPY2 } & \\
\end{array}$ & Z48510.1 & 100132596 & Up & Unknown & [87] \\
\hline
\end{tabular}

functioning either through transcriptional interference or chromatin modification that often recruits chromatin modification complexes for remodeling (e.g. XIST in mammals), or through binding to block pre-initiation complex (PIC). In contrast, trans-lncRNAs (trans-acting lncRNAs) can regulate the expression of distant gene loci (e.g. HOTAIR) [23].

\section{Mechanism of functioning}

LncRNAs roughly fall into three groups that influence transcriptional regulation, post-transcriptional regulation or other functions (Figure 2). Those that exert transcriptional regulation can be sub-divided into three major groups according to their action mechanisms: (1) transcriptional interference, (2) chromatin remodeling, and (3) those transcribed from enhancers, so-called enhancer RNAs (eRNAs), which activate gene transcription. Posttranscriptional regulation $\operatorname{lncRNAs}$ can be also divided according to the type of control exerted in: (1) splicing regulation, (2) translational control, and (3) competing endogenous RNAs (ceRNAs). LncRNAs that influence mRNA splicing may function by binding to or modulating splicing factors, or by directly hybridizing mRNA sequences to block splicing. LncRNAs that participate in translational control may function by binding to translation factors or ribosomes, or binding directly to the mRNA strand to promote its degradation similarly to siRNA (small-interfering RNA) [23]. Some lncRNAs, particularly pseudogenes, act as ceRNAs (competing endogenous RNAs), which function as miRNA-sequestering sponges to stimulate the abnormal expression of specific mRNAs that share common miRNA response elements (MREs). Therefore, downregulation of certain ceRNAs induces higher miRNA levels to bind mRNAs that contain the same MREs, thereby lowering tumor suppressor protein levels. Conversely, overexpression of ceRNAs leads to lower miRNA levels to bind mRNA, increasing expression of its protein $[20,29]$. Although the role of ceRNAs in oncogenesis is not fully understood, initial studies on GC suggest that this is a complementary mechanism for post-transcriptional regulation in cancer $[29,30]$. Some IncRNAs such as AC009499.1, GACAT1, GACAT3, H19, LINC00152, AP000288.2, FER1L4, and RP4-620F22.3 and some miRNAs miR-18a-5p, miR-18b-5p, miR-19a3p, miR-20b-5p, miR-106a-5p, miR-106b-5p, miR-31$5 \mathrm{p}$, miR-139-5p, and miR-195-5p have been involved in a clear cancer-associated ceRNA network [29]. For instance, lncRNA-FER1L4 possesses MREs to compete for miR$106 a-5 p$, thereby regulating the differential expression of PTEN, RB1, RUNX1, VEGFA, CDKN1A, E2F1, HIPK3, 
IL10, and PAK7 genes. Furthermore, cell experiments have shown that transfections with a FER1L4-siRNA simultaneously suppresses FER1L4 and RB1 mRNA levels [29].

Considering the limited currently available knowledge, some lncRNAs are difficult to categorize in a more "stable" group and thus we roughly place them into lncRNAs with "other functional mechanisms" [23] such as protein localization, telomere replication, RNA interference, beyond transcription and translation regulation, etc. Also, there are imprinting lncRNAs located in imprinted regions of the genome critical to maintaining parent-of-origin-specific gene expression. An example is H19, expressed on the maternal and paternal alleles, respectively, which maintains silencing of the IGF2 and KCNQ1 genes on those alleles [20].

\section{Targeting mechanisms of IncRNAs}

According to their action mechanism, lncRNAs may also be classified by their targeting features, mainly

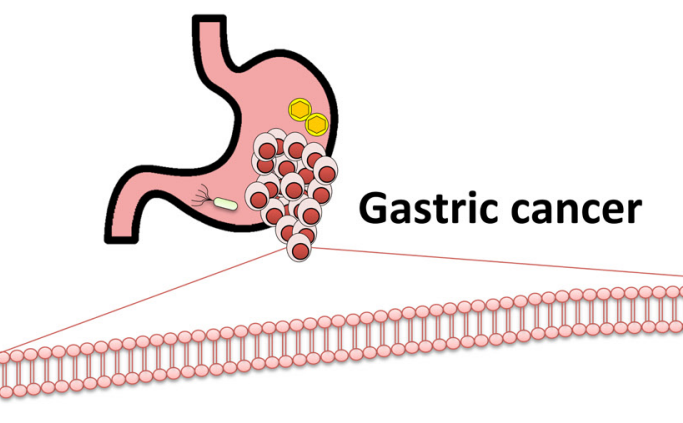

\section{Translational control}

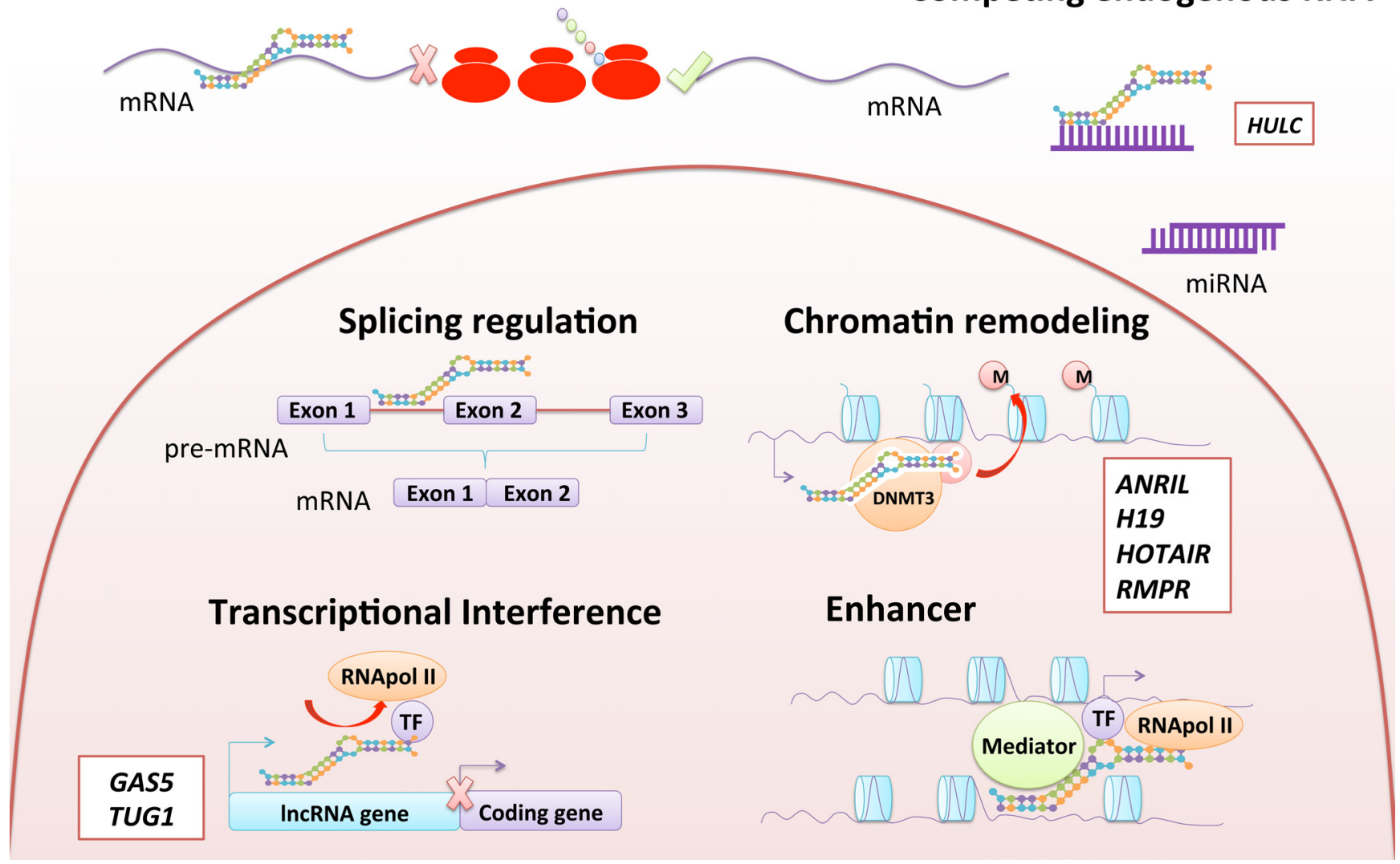

Competing endogenous RNA

Figure 2: Functional classification of IncRNA. LncRNA could be classified according to their function in two groups. The first group is composed of lncRNAs involved in "transcriptional regulation", including transcripts with transcriptional interference, chromatin remodeling, and enhancer functions. The second group consists of lncRNAs involved in "post-transcriptional regulation", including transcripts with splicing regulation, translational control and competing endogenous RNAs (ceRNAs). Some lncRNAs found altered in gastric cancer are shown in white boxes in the figure next to their potential functions. 
associated in the following categories: (1) signal: show cell type-specific expression and respond to diverse stimuli, (2) decoy: bind and titrate away a protein target, but do not exert any additional functions, (3) guide: bind proteins and then lead the localization of ribonucleoprotein complex to specific targets, (4) scaffold: serve as central platforms to combine multiple proteins to form ribonucleoprotein complexes. Alternatively, lncRNAs can be grouped by the interactions established with their targets: RNA-RNA pairings, RNA-DNA hybrids, RNA structure-mediated interactions and protein linkers. However, a single RNA archetype to explain their regulatory effects may not be sufficient to fully describe one lncRNA because a defined lncRNA may contain multiple archetypes. Many lncRNAs are induced by endogenous and exogenous signals, and with the binding sites for chromatin modification complexes (such as polycomb repressive complexes (PRC)) they can repress or activate the expression from a set of genes. Therefore, these lncRNAs operate as both signal and guide $[23,31]$.

\section{LNCRNAS IN GASTRIC CANCER}

Many studies in GC have begun performing highthroughput techniques such as RNA-seq or microarray to compare the expression profiles of lncRNAs in early/ advanced GC tumors with their paired non-cancerous samples. Then, those lncRNAs with significant foldchange values or with a particular characteristic in a different cohort of cases were validated mainly by quantitative-polymerase chain reaction (qPCR). Researchers usually relate lncRNAs expression values to clinical pathological features in patients and/or gene ontology to guide their functional assays and animal experiments. The results of some lncRNA differential expression analyses are in Table 1.

\section{Main IncRNAs involved in GC}

\section{XIST}

The $X$ inactive-specific transcript (XIST) is known for initiating $\mathrm{X}$-chromosome inactivation, recruiting polycomb repressive complex 2 (PRC2), and forming a transcriptionally silent nuclear compartment enriched by repressive chromatin modifications including H3K27me3 [32]. The localization to chromatin and gene expression silencing by XIST are mediated by different RNA domains: transcriptional silencing requires the A-repeat domain and interactions with nuclear matrixrelated proteins [32]. However, based on the expression profiles of several Y chromosome genes, some authors have speculated that XIST might silence genes on the Y chromosome through its role in histone modification and DNA methylation $[33,34]$.Yet there was a detectable level of XIST transcript in preneoplastic cells located in the gastric fundus of a male mouse infected with Helicobacter felis (a mouse model for Helicobacter pylori infection, which can lead to GC in humans) and, as expected, there was no XIST expression detected in the normal male mouse fundus [33, 35].

This approach was enhanced by Yang et al. [14], who applied a propagation algorithm to uncover the hidden lncRNA-disease associations in several types of cancer to construct an expression network. They found that 15 genes, including 4 lncRNAs and 11 protein-coding genes, are involved in GC. The association scores of these 15 genes were higher than unassociated genes. For those genes potentially implicated in GC, the rank of XIST was one, which means there is an important correlation between this lncRNA and these genes.

\section{HOTAIR}

The lncRNA HOX antisense intergenic RNA (HOTAIR) was identified in 2007 by Rinn et al. [36] and Woo and Kingston [37] as a 2158-nucleotide lncRNA that controls the HOX genes [36]. HOTAIR does not affect expression of the HOXC cluster in humans but rather leads to repression of a $40-\mathrm{kb}$ region of the HOXD cluster [36, 38]. In cancer, high HOTAIR levels have been widely linked to a high incidence of lymph node metastases [39], even in GC cases [40, 41]. Expression results have generally led to a consensus among different studies that there are significantly higher levels of HOTAIR in GC tissues and GC cell lines than in non-cancerous tissues or other controls [30, 40, 42-45]. These high HOTAIR values have also been correlated with some clinicopathological features in patients, particularly with tumor-node metastasis (TNM) stage, lymphovascular invasion and lymph node metastasis of gastric tumors, constituting a predictor of poor overall survival in GC patients [30, 40, 44].

Endo et al. [42] performed a correlation analysis demonstrating that the High HOTAIR group (HOTAIR/ GAPDH $>1$ ) showed significantly more venous invasion, frequent lymph node metastases and a lower overall survival rate in diffuse GC than the Low HOTAIR group (HOTAIR/GAPDH $<1$ ). They also transfected KATOIII cells with HOTAIR siRNAs, showing a significant reduction in colony formation. Then, MKN74 and KATO-III cells with an increased or suppressed HOTAIR expression were injected into the tail vein or peritoneal cavity of immunodeficient mice to examine the effect of this lncRNA on metastasis and peritoneal dissemination. HOTAIR-expressing MKN74 injected into the tail vein of mice formed more liver metastasis than the control [42]. In addition, the reduced expression of HOTAIR in KATO III suppressed peritoneal dissemination [42]. Xu et al. also observed that higher expression levels of HOTAIR were significantly correlated with lymph node metastasis, and TNM-stage HOTAIR expression was also assessed in five GC cell lines, being overexpressed in only AGS, SGC- 
7901, and HGC-27 cells. HOTAIR downregulation by siRNA in AGS cells resulted in a lower invasion and a decrease in invasiveness marker expression such as MMP1 and MMP3, as well as a decreased expression in some mesenchymal markers such as vimentin and $\mathrm{N}$-cadherin. Meanwhile, the expression of epithelial markers such as E-cadherin was elicited in response to HOTAIR silencing in both AGS and SGC-7901 cells. In addition, Xu et al. also demonstrated that HOTAIR suppression reduced the epithelial-to-mesenchymal transition (EMT) in AGS cells via its regulation on Snail, an EMT-related transcription factor [43]. In addition, Lee et al. studied the effect of HOTAIR on apoptosis, cell proliferation and cell cycle in GC by blocking HOTAIR expression through two siRNAs in four cell lines. These siRNAs significantly reduced cell viability in MKN28, MKN74, and KATO III cells, but not in AGS cells. These siRNAs also induced apoptosis in KATO III cells, and significantly decreased invasiveness and migration in MKN28 and AGS cells. Furthermore, both siRNAs led to the differential expression of EMT markers in MKN28 [44]. Results from Xu and Lee's groups further support the notion that HOTAIR is not only involved in apoptosis inhibition in GC, but also in invasiveness promotion and EMT progression $[43,44,46]$.

Recently, Liu et al. showed that HOTAIR overexpression promotes proliferation, migration and invasion of BGC-823 and SGC-7901 cells, whereas HOTAIR depletion inhibited both cell invasion and viability and induced growth arrest in vitro and in vivo. Therefore, the authors suggest that HOTAIR may act as a ceRNA by becoming a sponge for miR-331$3 p$, thereby modulating the expression of HER 2 and imposing an additional level of post-transcriptional regulation. Immunohistochemical assays and a bivariate correlation analysis confirmed the positive HOTAIR/ HER2 correlation, which was significantly associated with advanced GC [30]. Similarly, a potential cooperative expression has been established between HOTAIR and SUZ12 genes that may affect the epigenetic state of GC cells with subsequent phenotypic changes that lead to tumor progression [40].

HOTAIR has been also studied to find single nucleotide polymorphism (SNPs) genetic mutations. Guo et al. [47] performed a case-control study on a north China population to evaluate the possible association between haplotype-tagging single nucleotide polymorphism (htSNPs) of the whole HOTAIR sequence and the risk of gastric cardia adenocarcinoma (GCA) as well as functional effect of the susceptibility of the SNP rs 12826786 on HOTAIR gene expression. This research group used the polymerase chain reaction-restriction fragment length polymorphism (PCR-RFLP) method to examine the htSNPs genotype in 515 GCA patients and 654 control subjects and then qPCR to examine the expression of HOTAIR in 102 GCA patients. In three HOTAIR gene htSNPs (rs12826786 C > T, rs4759314 A > G, and rs $10783618 \mathrm{C}>\mathrm{T}$ ), only the $\mathrm{T}$ allele of rs 12826786 was found to increase the risk of developing GCA and was linked to smoking and the TNM stage. These results indicate that the functional genotype alteration of rs12826786 SNP may have a genotype-specific effect on HOTAIR expression [47].

\section{H19}

LncRNA H19 was discovered in 1991 by Bartolomei et al. [48] and has shown to be highly expressed in extraembryonic tissues, the embryo proper and most fetal tissues, but its expression is dramatically reduced after birth $[49,50]$. Recent studies have reported that H19 is overexpressed in several malignancies, suggesting that it may have oncogenic properties in such cancers [51-54]. In general, researchers have found that H19 levels are markedly higher in GC cell lines and tissues than normal controls $[55,56]$. Also, a high H19 expression has been correlated significantly with the number of lymph nodes, metastasis and advanced TNM stage of GC [57], suggesting H19 is involved in the molecular etiology of GC [55] through the regulation of critical events, specifically EMT and the mesenchymal-toepithelial transition (MET)[58]. Ectopic expression of H19 increased cell proliferation, whereas H19 siRNA treatment contributed to cell apoptosis in AGS cells, probably through an association between $\mathrm{H} 19$ expression and a partial p53 inactivation [55]. In SGC7901 cells, ectopic H19 overexpression could promote an increase in cell proliferation, migration, invasion and metastasis in vitro and in vivo [57]. Some network studies suggest that H19 has a strong relationship with miR-675, which may even be encoded by H19 [59-61]. Interestingly, knockdown of H19/miR-675 indicates a tumor suppressor effect in MKN45 cells [57]. Moreover, a co-expression analysis identified ISM1 as a binding protein of H19, and the CALN1 gene as a target of miR-675, which were correlated with corresponding expression levels. Although H19 and miR-675 are thought to function in a similar manner, these results suggest that $\mathrm{H} 19$ makes other contributions in addition to encoding miR-675 in GC: it mediates the direct upregulation of $I S M I$ and the indirect suppression of CALN1 expression via miR-675 [57]. Other studies have also found a high co-expression between $\mathrm{H} 19$ and miR675 , demonstrating that miR-675 is a pivotal mediator in H19-induced cell growth promotion in GC. As the RUNX1 gene has been shown to be a direct target of miR-675 and functional assays have confirmed that H19/miR-675/ RUNX1 pathway induces GC development, this pathway may serve as a potential target for GC therapy [62]. H19 has also been proposed as both a GC therapeutic target and diagnostic marker with uc001lsz due to its ability to differentiate GC from benign gastric diseases [56].

\section{LINC00152}

LINC00152 is a 828-nucleotide lncRNA [63] that has been found overexpressed in several types of 
malignancies [56, 64], including tumor tissues and some GC cell lines $[63,65,66]$. Its high expression has been correlated with clinicopathological features such as invasion [63] and larger tumor size [66] in GC patients. Recently, Zhao et al. performed a gene set enrichment analysis (GSEA) to determine the possible biological processes and signaling pathways in which LINC00152 might be involved. They used siRNAs to silence LINC00152 expression in HGC-27 and SGC-7901 cells, and found that this knockdown could effectively inhibit cell proliferation and colony formation, promote cell cycle arrest at the G1 phase, trigger late apoptosis, reduce the EMT program, and suppress cell migration and invasion. All this evidence shows that LINC00152 possesses a oncogenic role in GC and therefore may be an important therapeutic target in GC [66].

LINC00152 is also a potential diagnostic biomarker for GC, particularly in gastric juice and blood samples. Gastric juice samples from GC patients have significantly higher levels of LINC00152 than those from normal controls with an acceptable area under the ROC curve (AUC up to 0.645) [63]. Li et al. studied both the clinical significance of LINC00152 in plasma as a biomarker for the screening of $\mathrm{GC}$ and the possible mechanism underlying its stable existence in blood. They analyzed blood samples from patients with advanced GC, early GC, gastric epithelial dysplasia (GED) and healthy controls using qPCR and sequencing, showing that plasma LINC00152 levels were significantly higher in advanced GC than in early GC subjects and healthy controls. In addition, they also showed that LINC00152 levels were significantly lower in preoperative plasma samples than in their paired postoperative samples. However, there were neither significant differences of LINC00152 levels between GED patients and healthy controls, nor any association between plasma LINC00152 levels and clinicopathological features in advanced GC patients. The sensitivity and specificity of plasma LINC00152 in GC were 48.1 and $85.2 \%$, respectively; and with an AUC up to 0.675 . Otherwise, amounts of LINC00152 secreted into plasma were similar to those secreted within exosomes, which could indicate that plasma lncRNAs such as LINC00152 mainly exist in exosomes, which are the main factor for protecting plasma lncRNAs [67]. These findings mean lncRNAs from both plasma and exosomes, particularly LINC00152, have the potential to be applied in the diagnosis of GC as a new blood-based biomarkers.

\section{LncRNAs as prognostic/diagnostic markers of GC}

In recent years, various studies have described several up- or downregulated lncRNAs that seem to be important as diagnostic/prognostic markers. Some have been studied in tissue samples, blood samples or even in gastric juice samples to assess their effectiveness in detecting $\mathrm{GC}$ or pointing the course this disease could follow. In this area, lncRNAs such as HOTAIR, LINC00152, MEG3, nuRuPAR, PRNCR1, AC130710 have been described with a prognostic role, whereas others such as H19, LINC00152, AI364715, HMlincRNA717, uc001lsz, SUMO1P3, HULC, AA174084, ABHD11-AS1, BC031243 and RP11-356I2.2 have been described with a diagnostic significance in GC tissue samples.

\section{Tissue markers}

Among the downregulated lncRNAs in GC, the imprinted lncRNA maternally expressed gene 3 (MEG3) has been widely described due to its previous association with various human cancers [68]. MEG3 expression has been found more markedly decreased in GC tissues than in non-tumor tissues, having a significant correlation with TNM stages, depth of invasion, tumor size and poor prognosis in patients. Ectopic expression of MEG3 has inhibited cell proliferation, promoted cell apoptosis, and altered p53 expression in GC cell lines. Interestingly, 5'-aza-2'-deoxycytidine (5-aza-CdR) treatment showed that MEG3 expression may be modulated by DNA methylation [69]. With all these results, MEG3 has been proposed as a novel tumor-suppressor lncRNA [14, 68, 69] and as a prognostic biomarker in GC due to its control of cell proliferation and apoptosis in vitro [69]. Similarly, the newly discovered ncRuPAR, which can upregulate the protease-activated receptor-1 (PAR1) gene expression during embryonic growth, has been reported as repressed in GC tissues, showing a significant correlation with tumor invasion depth, lymph node metastasis, distant metastasis, tumor size, and TNM stage, and an inverse association with the protein levels of PAR-1 and vascular endothelial growth factor (VEGF) in immunohistochemistry. Interestingly, both PAR1 and VEGF mRNA levels were significantly higher in cancerous tissues compared with non-tumor tissues. These results suggest that ncRuPAR may inhibit GC by regulating $P A R 1$, serving as a potential marker for GC [70]. Another downregulated lncRNA in GC is AI364715, which was assessed in GC tissue, paired human healthy gastric mucosa and gastric precancerous lesions (dysplasia) tissue [71]. AI364715 expression was significantly more downregulated in GC than in noncancerous and dysplasia tissues, and closely linked to tumor size and differentiation, which suggests AI364715 as a potential biomarker for a GC diagnosis [71]. Yet the transcript HMlincRNA717 was also assessed in a cohort of human GC samples (313 cases) and five GC cell lines were found not only largely downregulated in GC tissues $(62.6 \%)$, but also in gastric precancerous lesions [72]. More importantly, HMlincRNA717 expression levels were significantly correlated with cancer distal metastasis, venous invasion, and nerve invasion, suggesting that this lncRNA may be heavily involved in cancer occurrence and progression and may be a new potential biomarker of early GC [72]. Conversely, Song et al. [56] found by microarray that HMlincRNA717 was among the most 
upregulated lncRNAs in GC. LncRNA AC096655.1002 has also been found significantly suppressed in GC samples, with a significant inverse correlation with lymph node metastasis, distant metastasis, TNM stages, and differentiation grade. The AUC of AC096655.1-002 was up to 0.731 , showing a remarkable improvement compared to the use of serum CEA, and has been proposed as a potential diagnostic biomarker for GC [73]. The lower expression of uc0011sz in GC tissues, however, has been associated with TNM stage. The positive detection rates for $\mathrm{H} 19$ and uc001lsz (74\% and $84.4 \%$, respectively) are higher than those of common gastric cancer biomarkers CEA (64.0\%) and CA19-9 (53.3\%), while AUC was up to $0.613,0.751$, and 0.761 for H19, uc001lsz, and the combination, respectively. Therefore, combined use of H19 and uc001lsz slightly increased the diagnostic value of conventional markers for GC. As the deregulation of uc001lsz is present in early cancer and precancerous lesions, this lncRNA may be a potential marker for early GC both alone and combined with H19 [27]. Other prognostic markers are oriented to detecting SNPs in lncRNA sequences. As the androgen receptor (AR) is intricately involved in the gender disparity, cell migration and invasion of GC, a SNP in the prostate cancer noncoding RNA 1 (PRNCR1) may activate $\mathrm{AR}$ and may induce an increased risk for GC. Through PCR-RFLP, it was found that patients with the rs13252298AG genotype displayed a 1.5 -fold increased risk of GC, suggesting that this SNP in PRNCR1 may be an early prognostic biomarker [74].

Among the upregulated IncRNAs in GC, the small ubiquitin-like modifier 1 pseudogene 3 (SUMO1P3), a type of pseudogene lncRNA that has gained notoriety due to its significantly high levels in GC tissues. SUMO1P3 expression levels were well correlated with tumor size, grade of differentiation, lymphatic metastasis, and invasion. The AUC value on the ROC curve was significantly up to 0.666 , suggesting that SUMO1P3 may be a potential biomarker in GC [75]. Another transcript, AC130710, has been also described as a potential marker for GC prognosis due to its significantly higher levels in gastric tumor tissues, with a strong relation to larger tumor size, TNM stage and distal metastasis [76]. Interestingly, assays in MGC-803 cells showed that AC130710 expression can be downregulated by miR-129-5p, which provides a therapeutic insight for this lncRNA [76]. Another interesting lncRNA in GC is HULC (highly upregulated in liver cancer) [77] that was significantly overexpressed in SGC7901, BGC823 and AGS cell lines, and in GC tissues compared to normal controls. This overexpression was correlated with lymph node metastasis, distant metastasis and advanced tumor node metastasis stages in clinical samples. An AUC up to 0.769 suggests that HULC is a good candidate biomarker for GC. In addition, as HULC overexpression promoted cell proliferation and invasion in SGC-7901 cells, and significantly inhibited cell apoptosis by activating autophagy in the same cells, this lncRNA might have also a function in gastric tumorigenesis [78].

\section{Blood and other fluid markers}

Several lncRNAs have been assessed not only in tissues but also in non-invasive samples like blood and/or gastric juice to simplify sample obtaining and enhance GC screening. These lncRNAs studied in blood and/or gastric juice include LINC00152, AA174084, ABHD11-AS1, BC031243, and RP11-356I2.2. For instance, lncRNA AA174084 was evaluated by qPCR as a potential marker for an early GC diagnosis in tissues, blood, and gastric juices from patients at each stage of gastric tumorigenesis. Tissue expression levels of AA174084 were significantly downregulated in $71 \%$ of $\mathrm{GC}$ tissues, showing a gradual increase through preneoplastic lesions. These AA174084 levels had significant, negative correlations with age, Borrmann type and perineural invasion. Plasma AA174084 levels in GC patients also dropped noticeably on postoperative day 15 compared to preoperative levels, and were associated with invasion and lymphatic metastasis. AA174084 levels in gastric juice from patients with GC were significantly higher than the levels in normal mucosa or in patients with minimal gastritis, gastric ulcers, or atrophic gastritis. Significantly, the AUC reached 0.848 , which reaffirms the usefulness of AA174084 as a promising marker for an early GC diagnosis [79]. Another IncRNA, ABHD11-AS1, was evaluated in 173 tissue samples and 130 gastric juices in patients with benign lesions, gastric dysplasia, gastric premalignant lesions, and GC. The ABHD11-AS1 levels were significantly higher in cancer tissues and gastric juices in GC patients than those samples obtained from individuals with normal mucosa or minimal gastritis, atrophic gastritis, or gastric ulcers. Interestingly, the ABHD11-AS1 levels were also associated with gender, tumor size, tumor stage, Lauren type, and blood CEA levels. More importantly, when using ABHD11-AS1 as a marker in gastric juice, the positive detection rate of early gastric cancer patients was $71.4 \%$, suggesting that ABHD11-AS1 in gastric juice might be a good biomarker in GC screening [80]. Another study conducted by Zeng et al. evaluated the lncRNA and mRNA expression profiles in GC serum samples during the process of cytoreductive surgery (CRS) and hyperthermic intraperitoneal chemotherapy (HIPEC) through microarray analysis. Eight differentially expressed lncRNAs were validated by qPCR in six pairs of GC serum samples after CRS+HIPEC compared to the matched serum sample before CRS+HIPEC. Results showed that lncRNAs BC031243 and RP11-356I2.2 were the most significantly upregulated lncRNAs [81].

\section{LncRNAs as therapeutic targets in GC}

Some lncRNAs have been proposed as therapeutic targets for GC due to their involvement in biological processes that induce carcinogenesis. For instance, ANRIL 
(also known as CDKN2B-AS1) has a higher expression in human GC tissues and in some GC cell lines, and was significantly correlated with TNM stage and tumor size, rendering it an independent predictor for overall survival. Transfection experiments using ANRIL siRNA in SGC-7901 and BGC-823 cells revealed a significant repression of cell proliferation in vitro and in vivo. This study also showed that E2F1 could induce ANRIL expression and thus ANRIL could silence miR-99a/miR449a epigenetically by binding to PRC2. As both miRNAs suppress the action of mTOR and CDK6/E2F1 pathways, ANRIL could indirectly induce cell proliferation through a positive feedback loop in GC, thereby constituting a potential target for new therapies in human GC [60]. Another lncRNA, AK058003, was proposed as a potential inductor of hypoxia and metastasis in GC. It is frequently upregulated in GC samples, promoting GC migration and invasion in vivo and in vitro through its regulation of the expression of metastasis-related gene $S N C G$. More interestingly, the SNCG gene was found significantly methylated in its $\mathrm{CpG}$ islands in AK058003-depleted GC cells. These results show how AK058003 contributes as a regulator of hypoxia signaling, and as a promising target for new therapies [82]. Similarly, lncRNA SPRY4 gene intronic transcript 1 (SPRY4-IT1) was found significantly elevated in GC tissues and cell lines, and was highly positively correlated with tumor size, invasion depth, distant metastasis, TNM stage, and reduced overall survival and disease-free survival. Additional in vitro assays showed that SPRY4-IT1 suppression significantly reduced cell proliferation, colony formation, and cell migration/invasion in MKN45 cells. These effects were partially mediated by the regulation of certain cyclins and matrix metalloproteinase (MMPs)-related genes, suggesting that SPRY4-IT1 is essential for GC tumorigenesis and may represent a novel therapeutic target in GC [83]. Conversely, Xie et al. found that this lncRNA is downregulated in $\mathrm{GC}$ and that this low expression of SPRY4-IT1 is involved in GC progression and metastasis [84]. The growth arrest-specific transcript (GAS5) lncRNA, however, was also found downregulated in GC tissues and in five GC cell lines. This downregulation was associated with larger tumor size and advanced pathological stage. Patients with lower GAS5 expression levels had significantly poorer disease-free survival and overall survival than those with high GAS5 expression, suggesting that the GAS5 decrease is an independent prognostic indicator for GC. The ectopic expression of GAS5 in BGC823 and SGC7901 cells demonstrated reduced cell proliferation and increased apoptosis induction both in vitro and in vivo when cells were transplanted into nude mice. Conversely, downregulation of endogenous GAS5 by siRNA treatment showed a promotion in MGC803 cell proliferation. The influence of GAS5 on GC cell proliferation could be mediated via regulating E2F1 and p21 expression, becoming not only a new prognosis marker but also a potential therapeutic target [85].

Recently, a new specific differentially-expressed lncRNA, LEIGC, was found among the four most significantly downregulated lncRNAs in GC, and this suppression was confirmed in a larger number of samples by qRT-PCR. Functional assays showed that overexpression of LEIGC suppressed cell proliferation, colony formation and migration in MGC-803 cells and enhanced the sensitivity of these cells to 5-fluorouracil (5-FU). Conversely, knockdown of LEIGC showed an increased tumor progression in NOD/SCID mice injected with previously transfected MGC-803 cells. Moreover, LEIGC inhibited EMT in GC, suggesting that it acts as a tumor-suppressor in $\mathrm{GC}$ and regulates cancer development and progression [86]. By contrast, some lncRNAs have been also found differentially expressed between GC in stage IV and non-stage IV, for example, special for distant metastasis of $G C$ (SDMGC), a putative regulator of TRIM16 gene, which was found by using a microarray platform followed by cis-acting and trans-acting analyses. Both, TRIM16 and SDMGC were more upregulated in the distant metastatic tissues and GC cell lines than primary GC tissues and GES-1 normal cell lines, respectively. SDMGC or TRIM16 silencing reduced cell invasion and migration, whereas upregulation of SDMGC or TRIM16 could promote cell invasion and migration in AGS and SGC-7901 cells [87].

\section{PERSPECTIVES}

Emerging data from high-throughput technologies have provided valuable insight into the GC-relevant molecular classification and intracellular pathways and this facilitates the development of novel GC-treatment strategies. However, late diagnosis and drug resistance remain significant challenges; therefore, there is a critical need for accurate early diagnosis tools and new cancer-cell-specific targets for therapy based on genetic or epigenetic markers, particularly in GC. Despite the development of more effective agents and the identification biomarkers that can be used for diagnosis, prognosis, and therapy, many of these strategies are generally only applicable to a limited number of patients with GC.

In recent years, long non-coding RNAs have garnered attention in many fields in a bid to understand various cell processes, particularly in cancer, where a marked deregulation in the expression pattern of these transcripts contributes to the onset and progression of malignancies.

Many initial lncRNAs, such as XIST and H19, were discovered in the 1980s and 1990s secondarily to the search in cDNA libraries for clones of interest in studies focused generally on the identification of new genes related to particular diseases. In the past decade, 
however, large-scale analyses have endeavored to identify ncRNA species comprehensively. This paradigm shift has been determined by dramatic advances in high-throughput technologies, including microarrays and next-generation RNA-Seq [20]. Conventional cDNA microarray designs initially detected only those transcripts represented by a few probes corresponding to lncRNAs. To solve this drawback, microarrays have been modified to detect the expression of IncRNAs, increasing exponentially the number of lncRNAs with aberrant expression in different cancer types. However, the most important progress has been the introduction and popularization of RNA-Seq as a standard tool in transcriptome studies, as this has removed many barriers to detecting all forms of RNA transcripts applied to an increasing number of tumor samples. RNA-Seq studies now suggest that several thousand uncharacterized lncRNAs are present in any given cell type, and elegant, large-scale analyses of lncRNAs in stem cells suggest that they may be an integral component of lineage specificity and stem cell biology. Other recently developed methods for profiling lncRNAs genome-wide have enhanced high-throughput identification of RNADNA and RNA-protein connections thanks to another important feature: their secondary structure [88-90]. ChIRP and CHART methods that use complementary oligonucleotides to pull down chromatin-related lncRNAs, can determine the chromatin-binding sites for lncRNAs. Alternatively, RNA immunoprecipitation sequencing (RIP-Seq) and photoactivatable ribonucleoside-enhanced crosslinking and immunoprecipitation (PAR-CLIP) complement the study of RNA-protein interactions. These new techniques are promising tools to explore the mechanisms that govern lncRNA-chromatin interactions, as demonstrated by the informative analyses performed to date on select lncRNAs [91].

The discovery of a massive number of lncRNAs that may contribute to the transformation and maintenance of cancer phenotypes has important clinical implications, opening up a broad range of new possibilities for cancer diagnostics and treatment. In this context, one of the most important distinctive features of lncRNAs is their highly tissue- and cell type-specific expression pattern, which could be useful as accurate biomarkers for cancer diagnostics or as therapeutic targets for cancer treatment. However, the functional modes of lncRNAs and the mechanisms by which they drive cancer are still largely unknown.

In terms of diagnosis, some of these cancer-specific lncRNAs can be detected in tissue, plasma, urine or even the gastric juice of cancer patients. In some cases, these lncRNAs have been shown to be more accurate than conventional GC tumor markers such as CEA and CA19.9 in a small number of samples $[56,73]$. Unfortunately, to sentence that IncRNAs are worse or better than other clinical, genetic or epigenetic markers requires more exhaustive clinical validation. Meanwhile these tools could function as complementary markers. Beyond detection and quantification of lncRNA expression in these clinical samples, the application of lncRNAs as biomarkers in daily practice can be challenging given their nature as long RNA molecules. The desirable markers should be stable and easily detectable in plasma or other body fluids to allow non-invasive diagnosis; therefore, a promising area of research focuses on using RNA molecules contained in exosomes, microvesicles, apoptotic bodies and apoptotic microparticles as biomarkers. These membranous particles are released by tumor cells and may contain tumor-specific lncRNAs protected from the RNases present in body fluids $[92,93]$.

In terms of therapy, current studies have been focusing on understanding the functional implications of lncRNAs, particularly their specific regulation in mRNA, miRNA or protein activity. As lncRNAs can control protein activity, drugs aimed at lncRNAs can be more refined and less toxic than conventional protein-targeting drugs. Another potential therapeutic benefit could be obtained through RNA-based therapeutic strategies, such as siRNA and microRNA, or using small molecule compounds designed specifically to act together with target lncRNAs or ribonucleoprotein complexes [20]. To solve the gene specificity limitations, gene knockout generated by directed targeting nucleases provides a powerful tool for elucidating the function of lncRNAs both in vitro and in vivo. In particular, genome editing by clustered regulatory interspaced short palindromic repeatsassociated endonuclease 9 (CRISPR-Cas9) is now carried out quickly and efficiently to generate total or partial deletion of lncRNAs, or to block lncRNA expression by the targeted interruption between the promoter and lncRNA sequence by inserting polyadenylation signals. CRISPR-Cas9 can also be applied to achieve lncRNA overexpression from its endogenous locus by inserting a strong promoter upstream or by targeting transcriptional activator complexes to the promoter [92, 94, 95]. However, the most widely applied strategy for gain-offunction studies is the induction of ectopic overexpression using transient or stable transfection or viral transduction. This may enhance the effect of IncRNAs when they exert their functions on trans, i.e., at a different location from the locus of transcription. Researchers have tried to solve some delivering drawbacks for these strategies in certain cancers with viral particles, non-viral particles or through synthetic delivery carriers such as galactosylated liposomes, poly-L-glutamic acid-coated liposomes, octaarginine (R8)-modified lipid nanoparticles, pHtriggered and PEGylated nanoparticles [96]. However, extensive investigation in animal models and clinical trials is needed to realize this extraordinary therapeutic potential.

The existence of thousands of IncRNAs participating in cell regulatory processes has important implications for what we think about cancer, compelling researchers to 
revise the current concept of disease, from its causative origins to treatment design and prescription. However, although the functions fulfilled by lncRNAs in GC have just begun to be revealed thanks to the rapid development of high-throughput detection technologies and available bioinformatics tools, this field is still in its infancy, and we are far from implementing lncRNAs clinically. To do so, drug treatments (either oligonucleotide-based or with small molecules) are needed that can manipulate lncRNA activity and deliver these molecules efficiently into cancer cells to ascertain their effect on tumors. An obvious requirement is a more comprehensive understanding of lncRNA functions and mechanisms under both physiological and pathological conditions. It is now necessary to move beyond the descriptive identification of cancer-related lncRNAs and concentrate on their function.

\section{ACKNOWLEDGMENTS}

This article was supported by the Chilean National Fund for Scientific and Technological Development (FONDECYT Iniciación No. 11150802 and FONDECYT Iniciación No. 11150622), and Project CORFO-CEGIN 09CN14-5960. Ismael Riquelme also thanks to the Postdoctoral Scholarship from the Universidad de La Frontera.

\section{CONFLICTS OF INTEREST}

There is no conflict of interest.

\section{REFERENCES}

1. Siegel R, Naishadham D, Jemal A. Cancer statistics, 2013. CA Cancer J Clin. 2013; 63:11-30.

2. Mickevicius A, Ignatavicius P, Markelis R, Parseliunas A, Butkute D, Kiudelis M, Endzinas Z, Maleckas A, Dambrauskas Z. Trends and results in treatment of gastric cancer over last two decades at single East European centre: a cohort study. BMC Surg. 2014; 14:98.

3. Riquelme I, Letelier P, Riffo-Campos A, Brebi P, Roa J. Emerging Role of miRNAs in the Drug Resistance of Gastric Cancer. Int J Mol Sci. 2016; 424.

4. Riquelme I, Tapia O, Leal P, Sandoval A, Varga MG, Letelier P, Buchegger K, Bizama C, Espinoza JA, Peek RM, Araya JC, Roa JC. miR-101-2, miR-125b-2 and miR$451 \mathrm{a}$ act as potential tumor suppressors in gastric cancer through regulation of the PI3K/AKT/mTOR pathway. Cell Oncol. 2016; 39:23-33.

5. Lim SM, Lim JY, Cho JY. Targeted therapy in gastric cancer: personalizing cancer treatment based on patient genome. World J Gastroenterol. 2014; 20:2042-2050.

6. Pasechnikov V, Chukov S, Fedorov E, Kikuste I, Leja M. Gastric cancer: prevention, screening and early diagnosis.
World J Gastroenterol. 2014; 20:13842-13862.

7. Park JY, von Karsa L, Herrero R. Prevention strategies for gastric cancer: a global perspective. Clin Endosc. 2014; 47:478-489.

8. Lee HS, Cho SB, Lee HE, Kim MA, Kim JH, Park do J, Kim JH, Yang HK, Lee BL Kim WH. Protein expression profiling and molecular classification of gastric cancer by the tissue array method. Clin cancer Res. 2007; 13:41544163 .

9. Riquelme I, Saavedra K, Espinoza JA, Weber H, García P, Nervi B, Garrido M, Corvalán AH, Roa JC, Bizama C. Molecular classification of gastric cancer: Towards a pathway-driven targeted therapy. Oncotarget. 2015; 6:24750-24779. doi: 10.18632/oncotarget.4990.

10. Nadauld LD, Ford JM. Molecular profiling of gastric cancer: toward personalized cancer medicine. J Clin Oncol. 2013; 31:838-839.

11. Yin Y, Li J, Chen S, Zhou T, Si J. MicroRNAs as diagnostic biomarkers in gastric cancer. Int J Mol Sci. 2012; 13:1254412555.

12. Lorincz AT. The Promise and the Problems of Epigenetics Biomarkers in Cancer. Expert Opin Med Diagn. 2011; 5:375-379

13. Gibb EA, Brown CJ, Lam WL. The functional role of long non-coding RNA in human carcinomas. Mol Cancer. 2011; 10:38.

14. Yang X, Gao L, Guo X, Shi X, Wu H, Song F, Wang B. A network based method for analysis of lncRNA-disease associations and prediction of IncRNAs implicated in diseases. PLoS One. 2014; 9:e87797.

15. Li T, Mo X, Fu L, Xiao B, Guo J. Molecular mechanisms of long noncoding RNAs on gastric cancer. Oncotarget. 2016; 7:8601-8612. doi: 10.18632/oncotarget.6926.

16. Cao J. The functional role of long non-coding RNAs and epigenetics. Biol Proced Online. 2014; 16:11.

17. Guttman M, Amit I, Garber M, French C, Lin MF, Feldser D, Huarte M, Zuk O, Carey BW, Cassady JP, Cabili MN, Jaenisch R, Mikkelsen TS, et al. Chromatin signature reveals over a thousand highly conserved large non-coding RNAs in mammals. Nature. 2009; 458:223-227.

18. St. Laurent G, Wahlestedt C, Kapranov P. The Landscape of long noncoding RNA classification. Trends Genet. 2015; 31:239-251.

19. Rinn JL, Chang HY. Genome regulation by long noncoding RNAs. Annu Rev Biochem. 2012; 81:145-166.

20. Prensner JR, Chinnaiyan AM. The emergence of lncRNAs in cancer biology. Cancer Discov. 2011; 1:391-407.

21. Nakagawa S, Kageyama Y. Nuclear lncRNAs as epigenetic regulators-beyond skepticism. Biochim Biophys Acta. 2014; 1839:215-222.

22. Da Sacco L, Baldassarre A, Masotti A. Bioinformatics tools and novel challenges in long non-coding RNAs (lncRNAs) functional analysis. Int J Mol Sci. 2012; 13:97-114. 
23. Ma L, Bajic VB, Zhang Z. On the classification of long noncoding RNAs. RNA Biol. 2013; 10:925-933.

24. Derrien T, Johnson R, Bussotti G, Tanzer A, Djebali S, Tilgner H, Guernec G, Martin D, Merkel A, Knowles DG, Lagarde J, Veeravalli L, Ruan X, et al. The GENCODE v7 catalog of human long noncoding RNAs: analysis of their gene structure, evolution, and expression. Genome Res. $2012 ; 22: 1775-1789$.

25. Pink RC, Wicks K, Caley DP, Punch EK, Jacobs L, Francisco Carter DR. Pseudogenes: Pseudo-functional or key regulators in health and disease? RNA. 2011; 17:792798.

26. Kung JTY, Colognori D, Lee JT. Long noncoding RNAs: past, present, and future. Genetics. 2013; 193:651-669.

27. He Y, Vogelstein B, Velculescu VE, Papadopoulos N, Kinzler KW. The antisense transcriptomes of human cells. Science. 2008; 322:1855-1857.

28. Faghihi MA, Wahlestedt C. Regulatory roles of natural antisense transcripts. Nat Rev Mol Cell Biol. 2009; 10:637643.

29. Xia T, Liao Q, Jiang X, Shao Y, Xiao B, Xi Y, Guo J. Long noncoding RNA associated-competing endogenous RNAs in gastric cancer. Sci Rep. 2014; 4:6088.

30. Liu X-H, Sun M, Nie F-Q, Ge Y-B, Zhang E-B, Yin D-D, Kong R, Xia R, Lu K-H, Li J-H, De W, Wang K-M, Wang Z-X. Lnc RNA HOTAIR functions as a competing endogenous RNA to regulate HER2 expression by sponging miR-331-3p in gastric cancer. Mol Cancer. 2014; 13:92.

31. Taft RJ, Pang KC, Mercer TR, Dinger M, Mattick JS. Non-coding RNAs: regulators of disease. J Pathol. 2010; 220:126-139.

32. Engreitz JM, Pandya-Jones A, McDonel P, Shishkin A, Sirokman K, Surka C, Kadri S, Xing J, Goren A, Lander ES, Plath K, Guttman M. The Xist lncRNA exploits threedimensional genome architecture to spread across the $\mathrm{X}$ chromosome. Science. 2013; 341:1237973.

33. Weakley SM, Wang H, Yao Q, Chen C. Expression and function of a large non-coding RNA gene XIST in human cancer. World J Surg. 2011; 35:1751-1756.

34. Cheetham SW, Gruhl F, Mattick JS, Dinger ME. Long noncoding RNAs and the genetics of cancer. Br J Cancer. 2013; 108:2419-2425.

35. Nomura S, Baxter T, Yamaguchi H, Leys C, Vartapetian AB, Fox JG, Lee JR, Wang TC, Goldenring JR. Spasmolytic polypeptide expressing metaplasia to preneoplasia in $\mathrm{H}$. felis-infected mice. Gastroenterology. 2004; 127:582-594.

36. Rinn JL, Kertesz M, Wang JK, Squazzo SL, Xu X, Brugmann SA, Goodnough LH, Helms JA, Farnham PJ, Segal E, Chang HY. Functional demarcation of active and silent chromatin domains in human HOX loci by noncoding RNAs. Cell. 2007; 129:1311-1323.

37. Woo CJ, Kingston RE. HOTAIR lifts noncoding RNAs to new levels. Cell. 2007; 129:1257-1259.

38. Zhang J, Zhang P, Wang L, Piao H, Ma L. Long non-coding RNA HOTAIR in carcinogenesis and metastasis. Acta Biochim Biophys Sin. 2014; 46:1-5.

39. Cai B, Wu Z, Liao K, Zhang S. Long noncoding RNA HOTAIR can serve as a common molecular marker for lymph node metastasis: a meta-analysis. Tumour Biol. 2014; 35:8445-8450.

40. Hajjari M, Behmanesh M, Sadeghizadeh M, Zeinoddini M. Up-regulation of HOTAIR long non-coding RNA in human gastric adenocarcinoma tissues. Med Oncol. 2013; 30:670.

41. Zhang S, Chen S, Yang G, Gu F, Li M, Zhong B, Hu J, Hoffman A, Chen M. Long noncoding RNA HOTAIR as an independent prognostic marker in cancer: a meta-analysis. PLoS One. 2014; 9:e105538.

42. Endo H, Shiroki T, Nakagawa T, Yokoyama M, Tamai K, Yamanami H, Fujiya T, Sato I, Yamaguchi K, Tanaka N, Iijima K, Shimosegawa T, Sugamura K, et al. Enhanced expression of long non-coding RNA HOTAIR is associated with the development of gastric cancer. PLoS One. 2013; 8:e77070.

43. Xu Z-Y, Yu Q-M, Du Y-A, Yang L-T, Dong R-Z, Huang L, Yu P-F, Cheng X-D. Knockdown of long non-coding RNA HOTAIR suppresses tumor invasion and reverses epithelial-mesenchymal transition in gastric cancer. Int $\mathrm{J}$ Biol Sci. 2013; 9:587-597.

44. Lee NK, Lee JH, Park CH, Yu D, Lee YC, Cheong J-H, Noh SH, Lee SK. Long non-coding RNA HOTAIR promotes carcinogenesis and invasion of gastric adenocarcinoma. Biochem Biophys Res Commun. 2014; 451:171-178.

45. Kladi-Skandali A, Michaelidou K, Scorilas A, Mavridis K. Long Noncoding RNAs in Digestive System Malignancies: A Novel Class of Cancer Biomarkers and Therapeutic Targets? Gastroenterol Res Pract. 2015; 2015:319861.

46. Liu Y, Sun M, Xia R, Zhang E, Liu X, Zhang Z, Xu T, De W, Liu B, Wang Z. LincHOTAIR epigenetically silences miR34a by binding to PRC2 to promote the epithelial-tomesenchymal transition in human gastric cancer. Cell Death Dis. 2015; 6:e1802. doi: 10.1038/cddis.2015.150.

47. Guo W, Dong Z, Bai Y, Guo Y, Shen S, Kuang G, Xu J. Associations between polymorphisms of HOTAIR and risk of gastric cardia adenocarcinoma in a population of north China. Tumour Biol. 2015; 36:2845-2854.

48. Bartolomei MS, Zemel S, Tilghman SM. Parental imprinting of the mouse H19 gene. Nature. 1991; 351:153155.

49. Poirier F, Chan CT, Timmons PM, Robertson EJ, Evans MJ, Rigby PW. The murine H19 gene is activated during embryonic stem cell differentiation in vitro and at the time of implantation in the developing embryo. Development. 1991; 113:1105-1114.

50. Tabano S, Colapietro P, Cetin I, Grati FR, Zanutto S, 
Mandò C, Antonazzo P, Pileri P, Rossella F, Larizza L, Sirchia SM, Miozzo M. Epigenetic modulation of the IGF2/H19 imprinted domain in human embryonic and extra-embryonic compartments and its possible role in fetal growth restriction. Epigenetics. 2010; 5:313-324.

51. Berteaux N, Aptel N, Cathala G, Genton C, Coll J, Daccache A, Spruyt N, Hondermarck H, Dugimont T, Curgy J-J, Forné T, Adriaenssens E. A novel H19 antisense RNA overexpressed in breast cancer contributes to paternal IGF2 expression. Mol Cell Biol. 2008; 28:6731-6745.

52. Berteaux N, Lottin S, Monté D, Pinte S, Quatannens B, Coll J, Hondermarck H, Curgy J-J, Dugimont T, Adriaenssens E. H19 mRNA-like noncoding RNA promotes breast cancer cell proliferation through positive control by E2F1. J Biol Chem. 2005; 280:29625-29636.

53. Luo M, Li Z, Wang W, Zeng Y, Liu Z, Qiu J. Upregulated H19 contributes to bladder cancer cell proliferation by regulating ID2 expression. FEBS J. 2013; 280:1709-1716.

54. Kim SJ, Park SE, Lee C, Lee SY, Jo JH, Kim JM, Oh $\mathrm{Y}-\mathrm{K}$. Alterations in promoter usage and expression levels of insulin-like growth factor-II and H19 genes in cervical carcinoma exhibiting biallelic expression of IGF-II. Biochim Biophys Acta. 2002; 1586:307-315.

55. Yang F, Bi J, Xue X, Zheng L, Zhi K, Hua J, Fang G. Up-regulated long non-coding RNA H19 contributes to proliferation of gastric cancer cells. FEBS J. 2012; 279:3159-3165.

56. Song H, Sun W, Ye G, Ding X, Liu Z, Zhang S, Xia T, Xiao $\mathrm{B}, \mathrm{Xi} \mathrm{Y}$, Guo J. Long non-coding RNA expression profile in human gastric cancer and its clinical significances. J Transl Med. 2013; 11:225.

57. Li H, Yu B, Li J, Su L, Yan M, Zhu Z, Liu B. Overexpression of IncRNA H19 enhances carcinogenesis and metastasis of gastric cancer. Oncotarget. 2014; 5:23182329. doi: 10.18632/oncotarget.1913.

58. Matouk IJ, Halle D, Raveh E, Gilon M, Sorin V, Hochberg A. The role of the oncofetal H19 lncRNA in tumor metastasis: orchestrating the EMT-MET decision. Oncotarget. 2016; 7:3748-65. doi: 10.18632/ oncotarget.6387.

59. Cai X, Cullen BR. The imprinted H19 noncoding RNA is a primary microRNA precursor. RNA. 2007; 13:313-316.

60. Gao W-L, Liu M, Yang Y, Yang H, Liao Q, Bai Y, Li Y-X, Li D, Peng C, Wang Y-L. The imprinted H19 gene regulates human placental trophoblast cell proliferation via encoding miR-675 that targets Nodal Modulator 1 (NOMO1). RNA Biol. 2012; 9:1002-1010.

61. Tsang WP, Ng EKO, Ng SSM, Jin H, Yu J, Sung JJY, Kwok TT. Oncofetal H19-derived miR-675 regulates tumor suppressor RB in human colorectal cancer. Carcinogenesis. 2010; 31:350-358.

62. Zhuang M, Gao W, Xu J, Wang P, Shu Y. The long noncoding RNA H19-derived miR-675 modulates human gastric cancer cell proliferation by targeting tumor suppressor RUNX1. Biochem Biophys Res Commun. 2014; 448:315-322.

63. Pang Q, Ge J, Shao Y, Sun W, Song H, Xia T, Xiao B, Guo $\mathrm{J}$. Increased expression of long intergenic non-coding RNA LINC00152 in gastric cancer and its clinical significance. Tumour Biol. 2014; 35:5441-5447.

64. Ji J, Tang J, Deng L, Xie Y, Jiang R, Li G, Sun B. LINC00152 promotes proliferation in hepatocellular carcinoma by targeting EpCAM via the mTOR signaling pathway. Oncotarget. 2015; 6:42813-42824. doi: 10.18632/ oncotarget.5970.

65. Cao W-J, Wu H-L, He B-S, Zhang Y-S, Zhang Z-Y. Analysis of long non-coding RNA expression profiles in gastric cancer. World J Gastroenterol. 2013; 19:3658-3664.

66. Zhao J, Liu Y, Zhang W, Zhou Z, Wu J, Cui P, Zhang Y, Huang G. Long non-coding RNA Linc00152 is involved in cell cycle arrest, apoptosis, epithelial to mesenchymal transition, cell migration and invasion in gastric cancer. Cell cycle. 2015; 14:3112-23. doi: 10.1080/15384101.2015.1078034.

67. Li Q, Shao Y, Zhang X, Zheng T, Miao M, Qin L, Wang B, Ye G, Xiao B, Guo J. Plasma long noncoding RNA protected by exosomes as a potential stable biomarker for gastric cancer. Tumour Biol. 2015; 36:2007-2012.

68. Zhou Y, Zhang X, Klibanski A. MEG3 noncoding RNA: a tumor suppressor. J Mol Endocrinol. 2012; 48:R45-53.

69. Sun M, Xia R, Jin F, Xu T, Liu Z, De W, Liu X. Downregulated long noncoding RNA MEG3 is associated with poor prognosis and promotes cell proliferation in gastric cancer. Tumour Biol. 2014; 35:1065-1073.

70. Liu L, Yan B, Yang Z, Zhang X, Gu Q, Yue X. ncRuPAR inhibits gastric cancer progression by down-regulating protease-activated receptor-1. Tumour Biol. 2014; 35:78217829.

71. Zhu S, Mao J, Shao Y, Chen F, Zhu X, Xu D, Zhang X, Guo J. Reduced expression of the long non-coding RNA AI364715 in gastric cancer and its clinical significance. Tumour Biol. 2015; 36:8041-5. doi: 10.1007/s13277-0153543-7.

72. Shao Y, Chen H, Jiang X, Chen S, Li P, Ye M, Li Q, Sun W, Guo J. Low expression of lncRNA-HMlincRNA717 in human gastric cancer and its clinical significances. Tumour Biol. 2014; 35:9591-9595.

73. Sun W, Wu Y, Yu X, Liu Y, Song H, Xia T, Xiao B, Guo J. Decreased expression of long noncoding RNA AC096655.1-002 in gastric cancer and its clinical significance. Tumour Biol. 2013; 34:2697-2701.

74. Li L, Jia F, Bai P, Liang Y, Sun R, Yuan F, Zhang L, Gao L. Association between polymorphisms in long non-coding RNA PRNCR1 in 8q24 and risk of gastric cancer. Tumour Biol. 2016; 37:299-303. doi: 10.1007/s13277-015-3750-2.

75. Mei D, Song H, Wang K, Lou Y, Sun W, Liu Z, Ding 
X, Guo J. Up-regulation of SUMO1 pseudogene 3 (SUMO1P3) in gastric cancer and its clinical association. Med Oncol. 2013; 30:709.

76. Xu C, Shao Y, Xia T, Yang Y, Dai J, Luo L, Zhang X, Sun W, Song H, Xiao B, Guo J. IncRNA-AC130710 targeting by miR-129-5p is upregulated in gastric cancer and associates with poor prognosis. Tumour Biol. 2014; 35:9701-9706.

77. Lu Z, Xiao Z, Liu F, Cui M, Li W, Yang Z, Li J, Ye L, Zhang $X$. Long non-coding RNA HULC promotes tumor angiogenesis in liver cancer by up-regulating sphingosine kinase 1 (SPHK1). Oncotarget. 2015; 7:241-254. doi: 10.18632/oncotarget.6280.

78. Zhao Y, Guo Q, Chen J, Hu J, Wang S, Sun Y. Role of long non-coding RNA HULC in cell proliferation, apoptosis and tumor metastasis of gastric cancer: A clinical and in vitro investigation. Oncol Rep. 2014; 31:358-364.

79. Shao Y, Ye M, Jiang X, Sun W, Ding X, Liu Z, Ye G, Zhang X, Xiao B, Guo J. Gastric juice long noncoding RNA used as a tumor marker for screening gastric cancer. Cancer. 2014; 120:3320-3328.

80. Yang Y, Shao Y, Zhu M, Li Q, Yang F, Lu X, Xu C, Xiao B, Sun Y, Guo J. Using gastric juice lncRNA-ABHD11AS1 as a novel type of biomarker in the screening of gastric cancer. Tumour Biol. 2016; 37:1183-8. doi: 10.1007/ s13277-015-3903-3.

81. Zeng X, Shi H, Wang J, Cui S, Tang H, Zhang X. Long noncoding RNA aberrant expression profiles after cytoreductive surgery and hyperthermic intraperitoneal chemotherapy of AGC ascertained by microarray analysis. Tumour Biol. 2015; 36:5021-5029.

82. Wang Y, Liu X, Zhang H, Sun L, Zhou Y, Jin H, Zhang H, Zhang H, Liu J, Guo H, Nie Y, Wu K, Fan D, et al. Hypoxia-inducible lncRNA-AK058003 promotes gastric cancer metastasis by targeting -synuclein. Neoplasia. 2014; 16:1094-1106.

83. Peng $\mathrm{W}, \mathrm{Wu} \mathrm{G}$, Fan $\mathrm{H}, \mathrm{Wu} J$, Feng J. Long noncoding RNA SPRY4-IT1 predicts poor patient prognosis and promotes tumorigenesis in gastric cancer. Tumour Biol. 2015; 36:6751-6758.

84. Xie M, Nie F, Sun M, Xia R, Liu Y, Zhou P, De W, Liu X. Decreased long noncoding RNA SPRY4-IT1 contributing to gastric cancer cell metastasis partly via affecting epithelial-mesenchymal transition. J Transl Med. BioMed Central Ltd; 2015; 13:250.

85. Sun M, Jin F, Xia R, Kong R, Li J, Xu T, Liu Y, Zhang E, Liu X, De W. Decreased expression of long noncoding RNA GAS5 indicates a poor prognosis and promotes cell proliferation in gastric cancer. BMC Cancer. 2014; 14:319.

86. Han Y, Ye J, Wu D, Wu P, Chen Z, Chen J, Gao S, Huang J. LEIGC long non-coding RNA acts as a tumor suppressor in gastric carcinoma by inhibiting the epithelial-tomesenchymal transition. BMC Cancer. 2014; 14:932.

87. Yan Y, Shen Z, Gao Z, Cao J, Yang Y, Wang B, Shen
C, Mao S, Jiang K, Ye Y, Wang S. Long noncoding ribonucleic acid specific for distant metastasis of gastric cancer is associated with TRIM16 expression and facilitates tumor cell invasion in vitro. J Gastroenterol Hepatol. 2015; 30:1367-1375.

88. Novikova I V, Hennelly SP, Sanbonmatsu KY. Sizing up long non-coding RNAs: do lncRNAs have secondary and tertiary structure? Bioarchitecture. 2012; 2:189-199.

89. Han P, Chang C-P. Long non-coding RNA and Chromatin Remodeling. RNA Biol. 2015; 12:1094-1098.

90. Quinn JJ, Ilik IA, Qu K, Georgiev P, Chu C, Akhtar A, Chang HY. Revealing long noncoding RNA architecture and functions using domain-specific chromatin isolation by RNA purification. Nat Biotechnol. 2014; 32:933-940.

91. Li C, Yang L, Lin C. Long noncoding RNAs in prostate cancer: Mechanisms and applications. Mol Cell Oncol. 2014; $1:$ e963469.

92. Huarte M. The emerging role of lncRNAs in cancer. Nat Med. 2015; 21:1253-1261.

93. Reis EM, Verjovski-Almeida S. Perspectives of Long NonCoding RNAs in Cancer Diagnostics. Front Genet. 2012; 3:32.

94. Liu G-Y, Zhao G-N, Chen X-F, Hao D-L, Zhao X, Lv X, Liu D-P. The long noncoding RNA Gm15055 represses Hoxa gene expression by recruiting PRC2 to the gene cluster. Nucleic Acids Res. 2015; 44:2613-2627.

95. Cheng AW, Wang H, Yang H, Shi L, Katz Y, Theunissen TW, Rangarajan S, Shivalila CS, Dadon DB, Jaenisch R. Multiplexed activation of endogenous genes by CRISPRon, an RNA-guided transcriptional activator system. Cell Res. 2013; 23:1163-1171.

96. Sun J, Bie B, Zhang S, Yang J, Li Z. Long non-coding RNAs: critical players in hepatocellular carcinoma. Int J Mol Sci. 2014; 15:20434-40438.

97. Zhang E, Yin D, Han L, He X, Si X, Chen W, Xia R, Xu T, Gu D, De W, Guo R, Xu Z, Chen J. E2F1-induced upregulation of long noncoding RNA LINC00668 predicts a poor prognosis of gastric cancer and promotes cell proliferation through epigenetically silencing of CKIs. Oncotarget. 2015; doi: 10.18632/oncotarget.6745.

98. Zhang E, Kong R, Yin D, You L, Sun M, Han L, Xu T, Xia R, Yang J, De W, Chen J fei. Long noncoding RNA ANRIL indicates a poor prognosis of gastric cancer and promotes tumor growth by epigenetically silencing of miR-99a/ miR-449a. Oncotarget. 2014; 5:2276-2292. doi: 10.18632/ oncotarget.1902.

99. Wang Y, Feng X, Jia R, Liu G, Zhang M, Fan D, Gao S. Microarray expression profile analysis of long noncoding RNAs of advanced stage human gastric cardia adenocarcinoma. Mol Genet genomics. 2014; 289:291-302.

100. Zhang Y, Song X, Wang X, Hu J, Jiang L. Silencing of LncRNA Hulc Enhances Chemotherapy Induced Apoptosis in Human Gastric Cancer. J Med Biochem. 2016; 35:137143. doi: 10.1515/jomb-2015-0016. 
101. Kurian L, Aguirre A, Sancho-Martinez I, Benner C, Hishida T, Nguyen TB, Reddy P, Nivet E, Krause MN, Nelles DA, Rodriguez Esteban C, Campistol JM, Yeo GW, et al. Identification of novel long noncoding RNAs underlying vertebrate cardiovascular development. Circulation. 2015; 131:1278-1290.

102. Kong R, Zhang E, Yin D, You L, Xu T, Chen W, Xia R, Wan L, Sun M, Wang Z, De W, Zhang Z. Long noncoding RNA PVT1 indicates a poor prognosis of gastric cancer and promotes cell proliferation through epigenetically regulating p15 and p16. Mol Cancer. 2015; 14:82.

103. Zhang X, Bu P, Liu L, Zhang X, Li J. Overexpression of long non-coding RNA PVT1 in gastric cancer cells promotes the development of multidrug resistance. Biochem Biophys Res Commun. 2015; 462:227-232. 